\title{
Feasibility Study and Impacts of EV Penetration in Rwanda's MV Distribution Networks
}

\author{
Emmanuel Mudaheranwa, Hasan Berkem Sonder, Liana Cipcigan \\ School of Engineering \\ Cardiff University \\ Cardiff, UK \\ Mudaheranwae@cardiff.ac.uk, HasanBerkemS@cardiff.ac.uk, Cipciganlm@cardiff.ac.uk
}

\begin{abstract}
Road transport has been identified as one of the top contributors of greenhouse gas (GHG) emissions from the energy sector in Rwanda [1]. The Ministry of Environment in its Third National Communication Report to the United Nations Framework Convention on Climate Change proposed different mitigation solutions including the introduction of electric vehicles (EVs) and fuel efficiency systems. The main motivation is to replace diesel-fuelled cars with EVs starting from 2020 in Rwanda [1]. EVs are projected to replace 150,000 passenger cars by 2050 and according to the projection, these EVs will require an average of $30 \mathrm{kWh}$ per $100 \mathrm{~km}$ [1]. In this paper, a feasibility study of introducing EVs in Rwanda's transport system is investigated. Simulation results show that $1.5 \%$ of the registered private vehicles, $10 \%$ of the registered buses and $10 \%$ of the registered taxis charging at $10 \mathrm{~kW}$ can be replaced with EVs with a minimal impact on voltage profiles. This study found that $1 \%, 8 \%$ and $8 \%$ of the registered private vehicles, buses and taxis can be supported with $20 \mathrm{~kW}$ chargers. However, an addition of two large-scale distributed generation (DG) units is required with $20 \mathrm{~kW}$ chargers in the network.
\end{abstract}

Keywords-Electric vehicles, Rwanda distribution network, load flow analysis, voltage control, power losses

\section{INTRODUCTION}

The road transport system in Rwanda is primarily composed of paved roads that lie between the capital, Kigali, and other major cities and towns in the country. It also contains 'unpaved' roads which makes the travel very challenging during wet seasons. Rwanda connects with neighbouring countries in East Africa by Great Lakes region and roads where most of the country's imports and exports are made. With the improvements in the past years, Rwanda's road network is expected to be upgraded to paved roads completely. The map in Fig. 1 shows the principal routes in Rwanda.

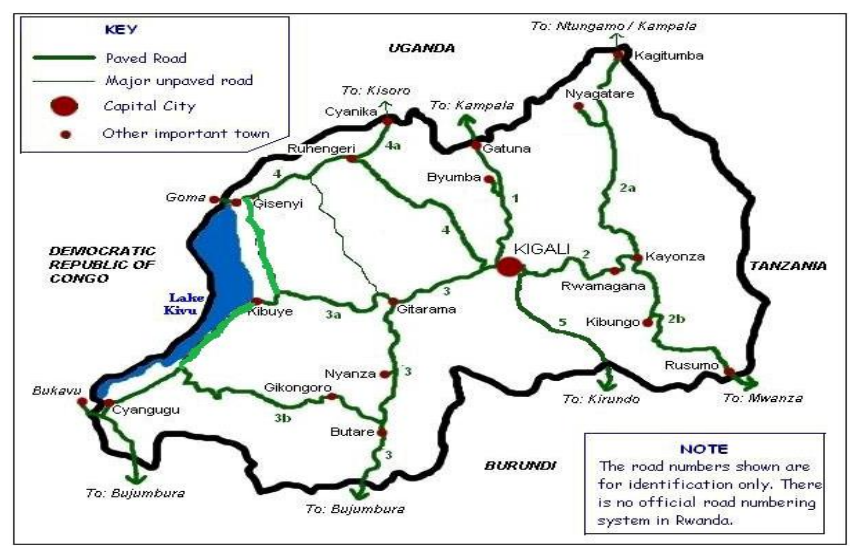

Figure 1: Principal travel routes shown in the map of Rwanda [2].
The total road network was covering up to $2,660 \mathrm{~km}$ and $11,350 \mathrm{~km}$ of paved roads and unpaved roads as of May 2018 [2].

One of the projects that the government of Rwanda has been working on is issuing national policy guidelines to eliminate fossil-fuelled two-wheelers and diesel-fuelled cars from its roads. This is the part of Rwanda's electrification strategy and it comprehensively focuses on the decarbonisation of the transport sector in the Eastern region of Africa. The president of Rwanda has revealed the plan of introducing electric motorcycles at a youth conference that took place in September 2019. According to [3], there are around 20-30,000 petrol/diesel-fuelled motorcycle taxis in Kigali alone. The President also assured his audience that there will be a way to replace all fossil-fuelled motorcycles in the future. The government's strategy focuses on replacing small passenger transport operators initially. Then, the plan is to replace buses, cars and taxis [3]. Fig. 2 shows one of the recent electric motorcycles introduced by Ampersand to replace the existing petrol-fuelled motorcycles.

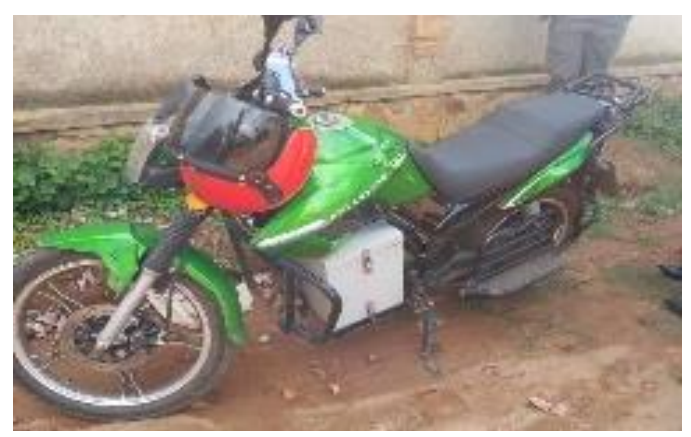

Figure 2: Electric motorcycle introduced by Ampersand.

It is assumed that once the policy is implemented, around 13,000 buses and 140,000 private cars will be electrified, this is equivalent to a total consumption of approximately 500 GWh by 2050 [1], [4].

Rwanda Environment Management Authority (REMA) revealed that road transportation, energy industries, manufacturing industries, and construction are the largest greenhouse gas (GHG) emitting sectors. The transportation sector contributes to the largest shares of GHG emission [1]. According to REMA, GHG emissions from the transportation sector are mainly due to fuel combustion activities of different vehicle categories. It is also evident that the deployment of electric cars and motorcycles with their charging technologies will significantly reduce the dependence on fossil fuels, and hence the GHG emissions. Fig. 3 shows the GHG emissions across different sectors between 2009 and 2015 in Rwanda. 


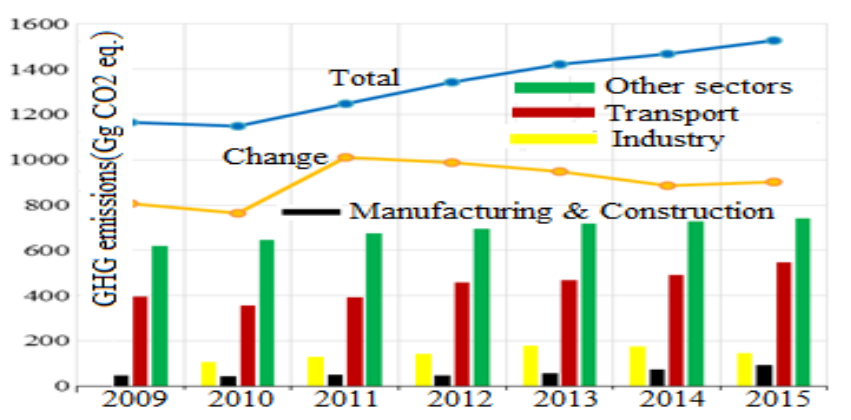

Figure 3: Shares of GHG emissions across sectors between 2009-2015 [1].

By achieving the decarbonisation of the transport sector, GHG emissions should be reduced significantly. However, EVs will require large shares of energy, and therefore, will introduce some significant distribution grid challenges: impact on steady state voltage profiles, increased network loading and phase imbalance in power networks. Furthermore, power quality issues may also arise due to high penetration of EVs and their charging technologies.

The total annual electrical energy demand for road transport is projected to be around $100 \mathrm{GWh}$ by 2030 (see Fig. 4). According to Fig. 4, the annual energy demand from the transportation sector is expected to increase to more than $500 \mathrm{GWh}$ (which is about $5 \%$ of the total demand) by 2050 [4].

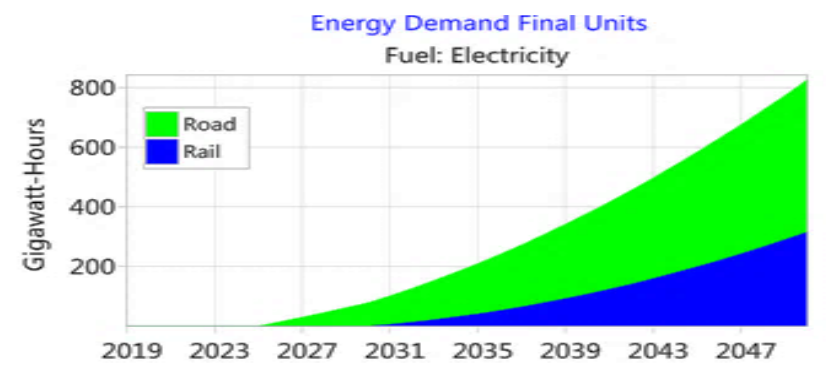

Figure 4: The annual growth in electrical energy demand by EVs and rail [5].

In order to meet high energy demands coming from the transportation sector, the government should establish and implement different policies to fund the development of EV infrastructure and ensure that the stability, reliability and security of power networks are maintained in Rwanda.

The daily traffic volume profile (see Fig. 5) is analysed to see how the total base network demand will change with the introduction of EVs. According to Fig. 5, three distinct peaks in Rwanda's traffic exist. These include morning off-peak when there is less car activity; morning-peak when people are travelling to work; and evening-peak hours when people are travelling back home in the evening.

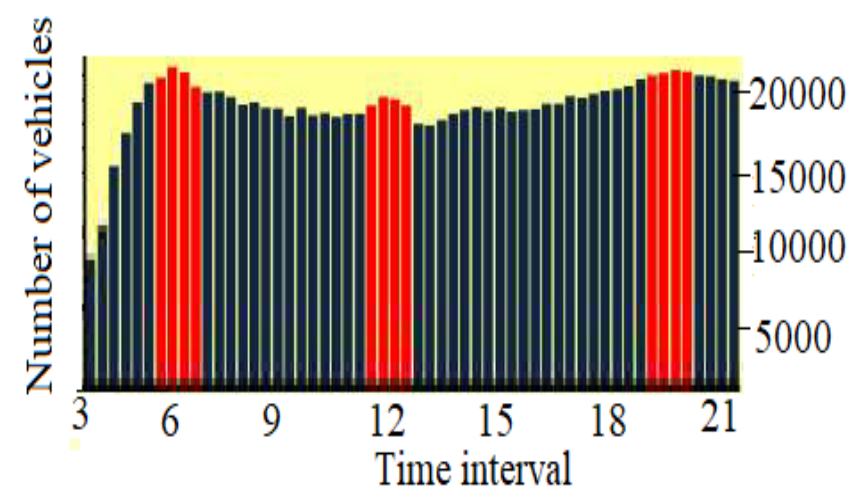

Figure 5: Profile of daily traffic volume [6].
The charging demand of EVs will be added to the base demand of the network. If EVs are charged during peak hours, the total network demand will be higher since the energy consumption is usually higher between 07:00-11:00 and 17:00-20:00 in Rwanda (see Fig. 6). The typical base load profile is presented in Fig. 6.

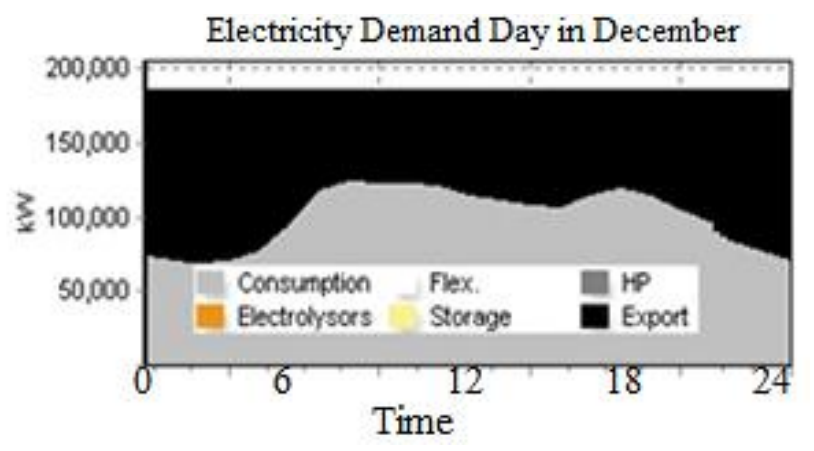

Figure 6: Power demand profile for Rwanda [4].

According to Fig. 6, the peak demand between 07:0011:00 and 17:00-20:00 will increase significantly with the large deployment of EVs into the network. This may introduce some challenges for electrical distribution networks in Rwanda. For this purpose, this paper analyses the impacts of connecting EVs and finds a realistic mitigation solution assisting the energy utility services to plan their generation and electricity networks in the future.

\section{RESEARCH ELABORATION}

\section{A. Rwanda's grid structure and typical load profile}

Since 2010, a total of $16,162 \mathrm{~km}$ has been developed for distribution networks for the purpose of transmitting the produced electricity to as many consumers as possible. Around $5,560 \mathrm{~km}(35 \%)$ of this operates at medium voltage (MV), whereas the rest operates at low voltage (LV) [7]. The MV level consists of $30 \mathrm{kV}, 17.32 \mathrm{kV} 15 \mathrm{kV}$ and $6.6 \mathrm{kV}$ lines covering Rwanda's current electricity network. According to the current electrification plan of Rwanda, a total of 10,160 $\mathrm{km}$ of MV lines should be installed to achieve up to $100 \%$ electricity access by 2024 . The LV network currently covers up to $10,572 \mathrm{~km}$, giving access to $42 \%$ of the entire households [7] . Fig. 7 shows the typical voltage levels in the distribution network with primary and secondary substations, and distribution level for customers connected at the LV level.

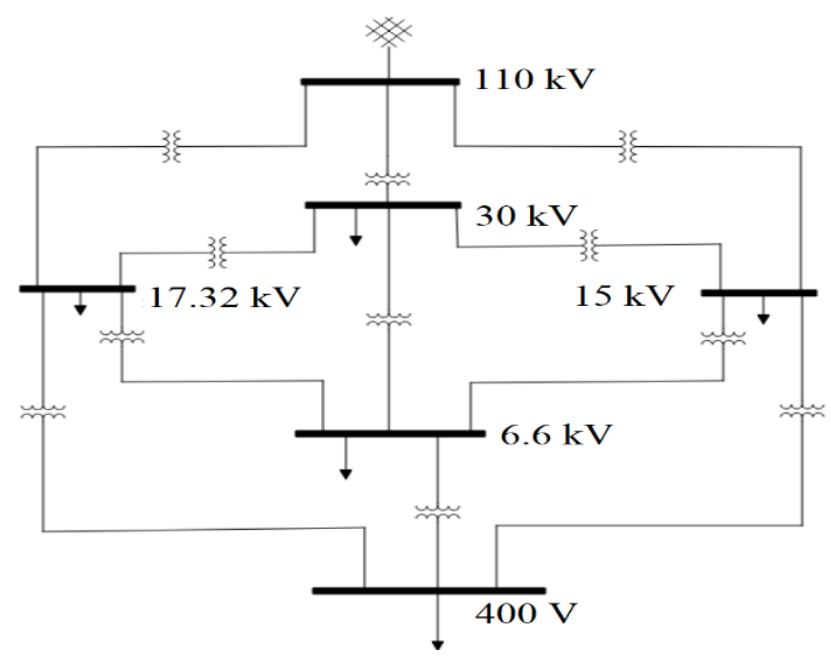

Figure 7: Voltage profile for Rwanda's distribution network [4]. 


\section{B. Modelling of network with different generation plants}

A real Rwanda electric distribution system is modelled in IPSA+ Power software tool. The generation mix includes a total of 29 hydropower plants with an installed capacity of 103.16 MW, and three diesel-based power plants with a total capacity of 58.8 MW [8]. However, due to the high operation costs, these diesel power plants only operate during peak hours to ensure the maximum use of hydro sources. In addition, there are four solar generators with a total installed and available capacity of $12.08 \mathrm{MW}$ and 1.9 MW [8]. The only peat fired plant provides a power of $14.25 \mathrm{MW}$ from an installed capacity of $15 \mathrm{MW}$. In addition, a methane-to-power plant, commissioned in December 2015, produces and supplies a total of 26.4 MW [9]. In general, all the existing generation plants in Rwanda including hydro, diesel, methane-to-power, peat-to-power and biomass can provide a total of 154.1 MW. However, the total installed capacity was recorded to be 221.9 MW as of June 2019 [10].

The network consists of 32 substations connected at different voltage levels. In this paper, only 18 substations are determined to be suitable connection points for EV chargers. Table I presents the base data of these 18 substations without any EV charger in the network.

TABLE I. SUBSTATION CHARACTERISTICS IN THE NETWORK

\begin{tabular}{|c|c|c|c|c|}
\hline $\begin{array}{c}\text { Substation } \\
\text { name }\end{array}$ & $\begin{array}{c}\text { Voltage } \\
(\mathbf{k V})\end{array}$ & $\begin{array}{r}\text { Rating } \\
\text { (kVA) }\end{array}$ & $\begin{array}{c}\text { Base Case } \\
\text { Demand } \\
(\mathrm{MW})\end{array}$ & $\begin{array}{c}\text { Base Case } \\
\text { Generation } \\
\text { (MW) }\end{array}$ \\
\hline 1 & 15 & 20 & 3.5 & 13 \\
\hline 2 & 15 & 10 & 1.2 & 2.4 \\
\hline 3 & 15 & 20 & 13 & 0 \\
\hline 4 & 15 & 10 & 7 & 25 \\
\hline 5 & 15 & 20 & 7 & 0 \\
\hline 6 & 15 & 10 & 25.8 & 11 \\
\hline 7 & 15 & 20 & 3 & 0 \\
\hline 8 & 30 & 2.5 & 2.1 & 0 \\
\hline 9 & 30 & 3.15 & 8 & 7 \\
\hline 10 & 30 & 5 & 3.4 & 0 \\
\hline 11 & 30 & 5 & 0.6 & 0 \\
\hline 12 & 15 & 45 & 4.8 & 4 \\
\hline 13 & 30 & 10 & 2.5 & 0 \\
\hline 14 & 30 & 1.5 & 6 & 0 \\
\hline 15 & 30 & 6 & 1.2 & 0 \\
\hline 16 & 6.6 & 5 & 4.7 & 0 \\
\hline 17 & 30 & 10 & 2.5 & 25 \\
\hline 18 & 6.6 & 6.6 & 3.5 & 0 \\
\hline Total & & & 99.8 & 87.4 \\
\hline
\end{tabular}

Each substation name is ordered from 1 to 18 with their names having been anonymised while collecting the data. Each substation has different consumption, generation and operating voltage level as shown in Table 1. For the purpose of load data collection, each connected load was modelled as constant power loads.

\section{Calculation and determination of transformer parameters}

Positive sequence resistance and reactance of distribution transformers are initially calculated by using their rated impedance and apparent power. The data only provided the rated impedance of each transformer in percentage. Therefore, per-unit equations are used to obtain the positive sequence characteristics of transformers and lines. Equation (1) is employed for this purpose [11].

$$
Z_{T}=\left(\frac{K_{V, r a t}}{K_{V}}\right)^{2} \times\left(\frac{K_{S}}{K_{S, r a t}}\right) \times Z_{T, r a t}
$$

where $Z_{T}, K_{V, \text { rat }}, K_{S, \text { rat }}$ and $Z_{T, \text { rat }}$ represent the calculated new per-unit impedance, transformer rated, transformer rated apparent power, and transformer rated impedance. In addition, $K_{V}$ and $K_{S}$ represent the base voltage and base apparent power, respectively. The standard $\mathrm{X} / \mathrm{R}$ ratio of transformers (ANSI/IEEE C37.5-1979) is used to calculate the resistance $R_{m(i, j)}$ and reactance $X_{m(i, j)}$ of the transformer ' $m$ ' between busbars $(i, j)$ as shown in Equations (2) and (3), respectively [12], [15].

$$
\begin{gathered}
R_{m(i, j)}=\frac{z_{T}}{\sqrt{\left[1+\left(\frac{X_{(i, j)} R_{(i, j)}}{\left.R_{(i, j)}\right]}\right.\right.}} \\
X_{m(i, j)}=\left(\frac{X_{(i, j)}}{R_{(i, j)}}\right) \times R_{m(i, j)}
\end{gathered}
$$

\section{Modelling of EV loads into the existing distribution network}

Each EV is modelled as a constant power, constant voltage for the power flow analysis using IPSA+ software tool. This option keeps the power on the grid-side constant during the charging process until the battery is fully charged. The power demand is modelled based on the charging patterns and operation models for EVs. These patterns are assumed to be night-charging and day-charging where the vehicles consist of private, bus and taxi cars. Fig. 8 shows the mode of operation for private, bus and taxi vars, respectively.

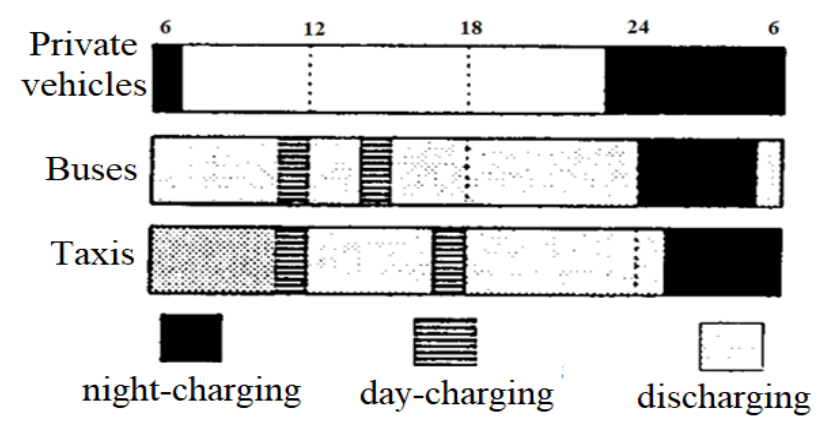

Figure 8: Mode of operation for each vehicle type.

The total power demand at time $t$ with EV charging is obtained from the following equation:

$$
P_{(p, b, T)}^{t}=P_{n}\left(n_{p}^{t}+n_{b}^{t}+n_{T}^{t}\right)
$$

where $P_{n}$ represents the nominal power of EV charger, $n_{p}^{t}, n_{b}^{t}$ and $n_{T}^{t}$ represent the total number of private vehicles, buses and taxis that are being charged at time $t$, respectively. In this paper, all EVs are assumed to have a power factor of 0.99 to 
represent simultaneous charging activities with maximum available energy consumption at specific points. In addition, all substations presented in Table I are used, and equal number of EVs are connected near the existing loads in those substations in the network.

\section{Simulation Results AND Discussion}

Different scenarios and case studies are modelled and conducted using IPSA+ software tool.

\section{A. EV charging scenarios and penetration into the network}

Based on the data obtained in 2016 in [13], [14] the total number of registered cars for private vehicles, buses and taxis are calculated for the current transportation sector in Rwanda. These are presented in Table II.

TABLE II. DISTRIBUTION OF PETROL VeHICLES IN RWANDA

\begin{tabular}{|c|c|c|}
\hline Vehicles types & Total & \% \\
\hline Private vehicles & 107,787 & 91.9 \\
\hline Buses & 5,180 & 4.4 \\
\hline Taxi & 4,288 & 3.7 \\
\hline Total & 117,255 & 100 \\
\hline
\end{tabular}

The real data in Table II shows the total number of registered petrol-fuelled vehicles in Rwanda as of 2019. Private vehicles have the largest contribution to the transport sector in Rwanda [16], whereas taxis have the smallest contribution.

Using the calculated data, two different scenarios are considered as follows:

- Scenario 1: All EVs in the network are charged using $10-\mathrm{kW}$ chargers.

- Scenario 2: All EVs in the network are charged using 20-kW chargers.

The number of EVs connected to 18 substations are kept the same for both scenarios; however, the total demand due to charging is larger in Scenario 2.

In addition, the total number of registered cars to be replaced with EVs are also calculated and shown in Table III.

TABLE III. SCENARIOS AND CALCULATED PENETRATION RATE

\begin{tabular}{|c|c|c|c|c|}
\hline \multirow{2}{*}{ Scenario } & \multicolumn{3}{|c|}{ EV penetration rate (\%) } & \multirow{2}{*}{$\begin{array}{c}\text { Total EV } \\
\text { charging } \\
\text { demand } \\
\text { (MW) }\end{array}$} \\
\cline { 2 - 5 } & Private cars & Buses & Taxis & (MW \\
\hline Scenario 1 & 1.5 & 10 & 10 & 27 \\
\hline Scenario 2 & 1 & 8 & 8 & 45 \\
\hline
\end{tabular}

Table III shows that the total demand by EV charging using $10-\mathrm{kW}$ and $20-\mathrm{kW}$ chargers are $27 \mathrm{MW}$ and $45 \mathrm{MW}$, respectively. In addition, the results showed that only $1.5 \%$ of the total private cars, $10 \%$ of the total registered buses, and $10 \%$ of the total registered taxis can be replaced with EVs without violating network operating limits for Scenario 1. Furthermore, for Scenario 2, the results showed that only $1 \%$ of the total private cars, $8 \%$ of the total registered buses, and $8 \%$ of the total registered taxis can be replaced with EVs without violating network operating limits.
In addition, simulation results showed that only 18 of the 32 substations in the whole network were suitable for the connection of $10-\mathrm{kW}$ and $20-\mathrm{kW}$ chargers, respectively. In addition, this study determined the suitable EV connection substations by prioritising urban areas (i.e., bigger cities) to make a realistic case. With reference to Table I, Table IV shows the total demand of these 18 substations with the connection of EVs in different scenarios.

TABLE IV. POWER CONSUMPTION IN EACH CHARGING SUbSTATION

\begin{tabular}{|c|c|c|}
\hline $\begin{array}{l}\text { Substation } \\
\text { name }\end{array}$ & $\begin{array}{c}\text { Scenario 1: Total } \\
\text { consumption with } \\
\text { EVs } \\
{[\mathrm{MW}]}\end{array}$ & $\begin{array}{c}\text { Scenario 2: Total } \\
\text { consumption with } \\
\text { EVs } \\
{[\mathrm{MW}]}\end{array}$ \\
\hline 1. & 5.0 & 6.0 \\
\hline 2. & 2.7 & 3.7 \\
\hline 3. & 9.0 & 10.0 \\
\hline 4. & 8.5 & 9.5 \\
\hline 5. & 8.5 & 9.5 \\
\hline 6. & 25.6 & 26.6 \\
\hline 7. & 4.5 & 5.5 \\
\hline 8. & 3.6 & 3.6 \\
\hline 9. & 9.0 & 10.0 \\
\hline 10. & 4.9 & 5.4 \\
\hline 11. & 2.1 & 3.1 \\
\hline 12. & 6.3 & 7.3 \\
\hline $13 .$. & 4.0 & 5.0 \\
\hline 14. & 7.5 & 8.5 \\
\hline 15. & 2.7 & 3.7 \\
\hline 16. & 4.7 & 5.7 \\
\hline 17. & 4.0 & 5.0 \\
\hline 18. & 5.9 & 6.9 \\
\hline Total & 118.5 & 135 \\
\hline
\end{tabular}

B. Impact of different scenarios on voltage profiles

In Rwanda, the voltage limits at the distribution level should be within acceptable limits of 1.044 p.u. and 0.933 p.u. The voltage results (see Fig. 9) showed that most busbars will experience voltage fluctuations after the connection of $10 \mathrm{~kW}$ and $20 \mathrm{~kW}$ chargers in the network. According to Fig. 9, the minimum voltage drop occurs at substations 3 and 18, whereas the maximum voltage drops due to EVs occur at substations 10, 12 and 16 respectively. However, all substations maintain to operate within strict limits for all scenarios. Some substations maintain constant voltage profiles under Scenario 2 due to the implementation of largescale distributed generation (DG) units.

\section{Voltage profiles in each scenario \\ Load connection point \\ $\begin{array}{llllllllllllllllll}1 & 2 & 3 & 4 & 5 & 6 & 7 & 8 & 9 & 10 & 11 & 12 & 13 & 14 & 15 & 16 & 17 & 18\end{array}$}

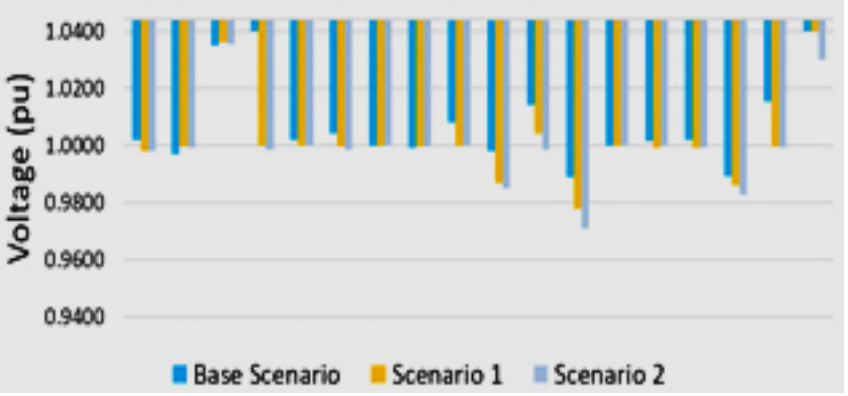

Figure 9: Voltage changes in different scenarios. 
Substations 3 and 18 are the least affected points in the network and the voltage drop is less than $1 \%$ because these points are located near the largest generation plants. In addition, substations experiencing the highest voltage drops (i.e. 10,12 and $16^{\text {th }}$ substations) are located farther away from the largest generation stations. Lastly, the lowest voltage drop is less than $1 \%$, whereas the highest is around $8 \%$ with DGs.

\section{Impact of different scenarios on load profiles}

Load profiles without and with the connection of EVs are obtained for the practical network in Figs. 10 and 11.

\section{EV demand profile}

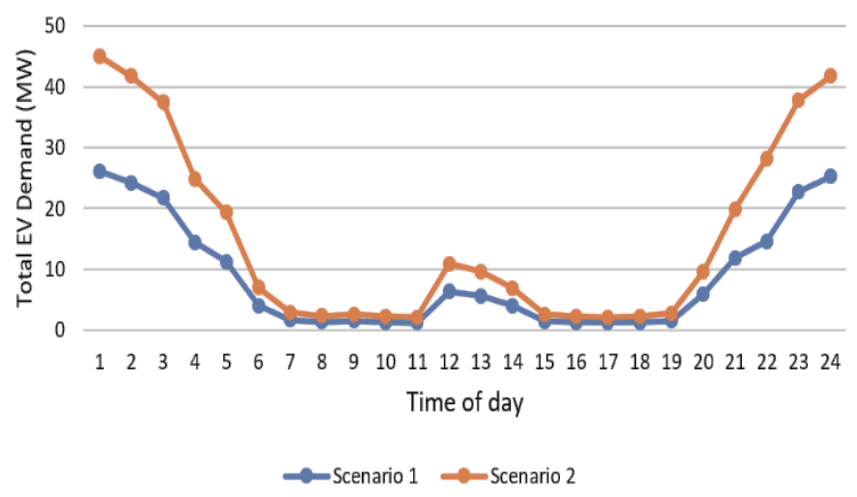

Figure 10: Daily demand profile of EVs in different scenarios.

The daily consumption profile of EVs represented in Fig. 10 shows a maximum demand of $45 \mathrm{MW}$ for Scenario 2 and 27 MW for Scenario 1 due to constant charging. The maximum charging demand occurs between 23:00-03:00 for both scenarios since the charging events are mainly assumed to occur during midnight (as shown in Fig. 8). In addition, the minimum charging demand is between 07:00-11:00 and 15:00-19:00 and the minimum EV demand is around 1.2 MW and 1.8 MW for Scenario 1 and Scenario 2, respectively.

The effect of EV charging on the total base network demand is also analysed (see Fig. 11).

\section{Load profile for each scenario}

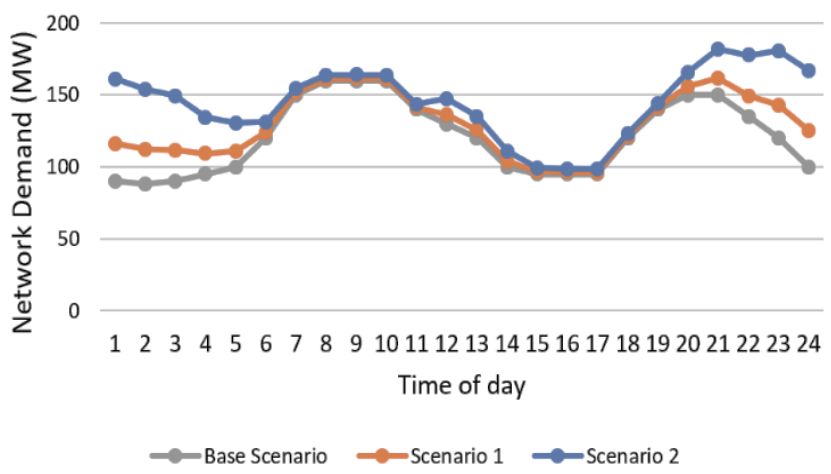

Figure 11: Total network demand with the connection of EVs in different scenarios.

The results show that additional power consumption due to EVs does not affect the shape of load demand curves for the base case; however, it affects the magnitude of peak demand significantly. According to Fig. 10, the total network demand significantly increases from $100 \mathrm{MW}$ to $180 \mathrm{MW}$ during late hours of the night. Furthermore, the demand remains closer to the base case during day hours. It may also be seen that the simultaneous charging during the night-time seems to be a challenge for the energy providers in Rwanda.
For this reason, in this study it is suggested the connection of two large-scale DG units near critical and congested substations for both scenarios. Simulation results showed that the connection of DG units in populated and congested areas facilitate the connection of EV chargers and improve voltage profiles by $1-3 \%$. In addition, simulation results showed that total network losses are significantly higher in Scenario 2 compared to Scenario 1 and base case since the grid has to meet a larger amount of demand instantly. Table $\mathrm{V}$ presents the implementation and impact of connecting DG units on network losses due to overloading.

TABLE V. NETWORK LOSSES IN DIFFERENT SCENARIOS

\begin{tabular}{|c|c|c|c|c|}
\hline Scenario & \multicolumn{3}{|c|}{ Total network losses (MW) } & $\begin{array}{c}\text { DG } \\
\text { connection } \\
\text { substation }\end{array}$ \\
\cline { 2 - 5 } & $\begin{array}{c}\text { With } \\
\text { DGs }\end{array}$ & $\begin{array}{c}\text { No } \\
\text { DGs }\end{array}$ & $\begin{array}{c}\text { Additional DG size } \\
(M W)\end{array}$ & \\
\hline Base & - & 45 & - & - \\
\hline 1 & 46.9 & 53.4 & 6.5 & 1 \\
\hline 2 & 47.9 & 72.4 & & 1 and 2 \\
\hline
\end{tabular}

In Rwanda, the total network losses are around 22\% [4], and in this study, the losses were obtained to be $23 \%$ during base case scenario when the network has no EV. For Scenario 1, one unit of 6.5 MW installed capacity was used to support the connection of EV chargers. In addition, a total capacity of 24.5 MW was provided by DG units for Scenario 2 to facilitate the connection of EVs and prevent and improve voltage violations and increased network losses. The results showed that with the connection of DG units, up to $34 \%$ of the losses can be reduced for the worst-case scenario.

\section{CONCLUSION}

This modelling study shows the integration of different types of EVs into Rwanda's transport and electricity systems. The electric vehicles are modelled in terms of power demand by considering their operation characteristics and utilisation patterns of the existing traffic volume. The probable daily demand analysis was obtained using the daily load profile in Rwanda that was extracted from the projected daily load curves of December 2019.

A change in load demand due to the introduction of EVs and their chargers into the transport system may introduce new peak loads leading to voltage drops and increased power losses in urban areas where larger commercial/industrial and EVs are connected. Simulation results showed that the addition of hundreds of $10-\mathrm{kW}$ chargers in 18 substations is only possible with the connection of a DG unit (6.5 MW). In addition, upgrading the $10-\mathrm{kW}$ chargers with $20-\mathrm{kW}$ chargers in the same substations will introduce some challenges for the network. The integration of $20-\mathrm{kW}$ chargers in urban areas can only be achieved with the connection of two large-scale DG units.

The study has shown that $1.5 \%, 10 \%$ and $10 \%$ of the total registered private cars, buses and taxis can be replaced with $10-\mathrm{kW}$ chargers, whereas $1 \%, 8 \%$ and $8 \%$ of the total registered private cars, buses and taxis can be replaced with 20-kW chargers in the Rwandan's transport sector. 


\section{ACKNOWLEDGEMENT}

The authors gratefully acknowledge the Commonwealth Scholarship Commission [17] in the UK for the sponsorship. We also appreciate the contributions of Rwanda Energy Group (REG), the Ministry of Infrastructures (MINENFRA), and Rwanda Environment Management Authority (REMA) for helping with the data collection.

\section{REFERENCES}

[1] R. E. M. Authority, "Third National Communication Report to the United Nations Framework Convention on Climate Change," Kigali, 2018.

[2] RTDA, “Annual Report, Fiscal Year 2017/2018,” Kigali, 2018.

[3] VOA, "Rwanda Encourages Youth to Use Electric Motorcycles," 2019.

[4] E. Mudaheranwa, "Rwanda's energy profile and potential renewable energy resources mapping toward sustainable development goals," in 2019 IEEE PES \& IAS PowerAfrica, Abuja, 2019.

[5] MINENFRA, "Energy sector strategic plan 2018/2019-2023/2024," Kigali, 2019.

[6] N. V. ZYL, "Planning of a public transport system for the city of Kigali, Rwanda," in 33rd Southern African Transport Conference (SATC 2014), Pretoria, 2014
[7] R. E. Group, "Evolution of Power Transmission Network,", Rwanda Energy Group, October 2019. [Online]. [Accessed October 2019].

[8] REG, Least Cost Power Development Plan: June 2019, Kigali, 2019.

[9] MINENFRA, 25 September 2019. [Online]. Available: http://www.mininfra.gov.rw/index.php?id=83. [Accessed 25 September 2019].

[10] REG, Least Cost Power Development Plan 2: June 2019, Kigali, 2019.

[11] S. S.Ramar, Power System Analysis, Delhi: PHI Learning Private Limited, 2013.

[12] A. N. Standard, guide for calculation of fault currents for application of ac high-voltage circuit breakers rated on a total current basis, IEEE, Inc, 1979.

[13] MINENFRA, Strategic Transport Plan for EDPRS2, Kigali, 2018.

[14] Newtimes, "New VW Rwanda plant to start production with 1000 cars annually," 2016.

[15] X.Liang, "Probabilistic generation and transmission planning with renewable energy integration," in 2017 IEEE Industrial and Commercial Power Systems (I\& CPS), Niagara Falls, 2017.

[16] Republic, "Consulting Services for the Planning and Design of a Public Transport System for Kigali City,” Kigali, 2012.

[17] Commonwealth Scholarship Commission in the UK, 2020. [Online]. Available: http://cscuk.dfid.gov.uk/about-us/contact-us/. [Accessed 5 March 2020]. 